\title{
Wheelchair axle position effect on start-up propulsion performance of persons with tetraplegia
}

\author{
Orestes Freixes, PT; ${ }^{*}$ Sergio Anibal Fernández, PT; ${ }^{1}$ Marcelo Andrés Gatti, PT; ${ }^{1}$ Marcos José Crespo, MSc; ${ }^{2}$ \\ Lisandro Emilio Olmos, MD; ${ }^{3}$ Iván Federico Rubel, MD $^{4}$ \\ ${ }^{1}$ Physical Therapy Unit, ${ }^{2}$ Gait Analysis Laboratory, ${ }^{3}$ Department of Rehabilitation Medicine, and ${ }^{4}$ Department of \\ Orthopaedics, Fleni Institute, Escobar, Argentina
}

\begin{abstract}
This repeated measures study assessed the changes in speed, acceleration, stroke frequency, and shoulder range of motion (ROM) associated with different wheelchair axle positions in people with chronic cervical (C) 6 tetraplegia. Our main hypothesis is that the up and forward axle position is the most conducive to wheelchair propulsion, increasing speed and acceleration with a lower stroke frequency. In a chronic spinal cord injury (SCI) unit, we measured the speed, acceleration, stroke frequency, and shoulder ROM in four different axle positions in eight subjects with C6 SCI. We analyzed two startup strokes over a smooth, level vinyl floor in the Motion Analysis Laboratory (Fleni Institute; Escobar, Argentina). We analyzed data for significant statistical differences using the Wilcoxon signed rank test and the Friedman test. Our study showed that the up and forward axle position results in an increase of speed and acceleration, with a higher stroke frequency and a decreased shoulder ROM. In addition, the down and backward axle position results in the lowest speed and acceleration, with a lower stroke frequency and an increased shoulder ROM. The up and forward axle position was the most conducive to stroke compared with other positions we analyzed.
\end{abstract}

Key words: ASIA C6, axle position, kinematic, propulsion, spinal cord injury, stroke frequency, tetraplegia, wheelchair, wheelchair acceleration, wheelchair speed.

\section{INTRODUCTION}

Most patients with spinal cord injury (SCI) use manual wheelchairs. A number of studies on people with para- plegia have studied upper-limb kinematics [1-2], forces applied on the wheelchair pushrim [3-4], propulsion patterns [5], and muscle activity during propulsion [6-8]. Researchers have focused on different variables, such as hand-rim size, wheel camber, rim tube diameter, and seat position, to determine how different wheelchair configurations may affect energy expenditure and mechanical efficiency of wheelchair propulsion [9-13].

Based on the evidence, we recommended adjusting the rear axle as far forward as possible without compromising the stability of the user. A more up and forward axle position decreases rolling resistance and therefore increases propulsion efficiency. It increases the handcontact angle or amount of the pushrim used by the individual. It has also been related to lower peak forces, less rapid loading of the pushrim, fewer strokes to go at the same speed, and greater hand-contact angles [5]. However, most of these studies were performed on people with paraplegia. A study by Cowan et al. performed in older adults analyzed the wheelchair configuration and

Abbreviations: ASIA = American Spinal Injury Association, $\mathrm{C}=$ cervical, $\mathrm{ROM}=$ range of motion, $\mathrm{SCI}=$ spinal cord injury. *Address all correspondence to Orestes Freixes, PT; Physi-

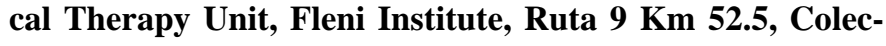
tora Este, Escobar, Buenos Aires 1625, Argentina; +54115777-3200; fax: +5411-5777-3200.

Email: ofreixes@fleni.org.ar

DOI:10.1682/JRRD.2009.09.0146 
determined that the greatest reductions in peak forces occur in lighter chairs with anterior axle positions [14].

According to Dalyan et al., a poor initial adaptation to the wheelchair often resulted in upper-limb pain and dysfunction [15]. This was particularly true for people with tetraplegia who had an even higher prevalence of shoulder pain than people with paraplegia [15-16]. A kinetic study of wheelchair propulsion of people with tetraplegia showed higher shoulder-joint reaction forces during contact with the pushrim [17]. Newsam et al. compared the temporal-spatial characteristics of wheelchair propulsion in people with low paraplegia, high paraplegia, cervical (C) 7 tetraplegia, and C6 tetraplegia and established that in people with C6 tetraplegia, propulsion velocities were significantly slower than all other groups [18]. We know that people with motor C6 tetraplegia represent a special subset of patients, given their multiple deficits in muscle strength imposed by their level of SCI [19]. In this particular group of people, it is of utmost importance to maximize propulsion efficiency. To the best of our knowledge, no publications comparing different axle positions focus on patients with C6 motor SCI.

Our study assessed the changes in speed, acceleration, stroke frequency, and shoulder range of motion (ROM) associated with four different wheelchair axle positions in people with chronic C6 tetraplegia. Our main hypothesis is that the up and forward axle position is the most conducive to wheelchair propulsion, increasing speed and acceleration with a lower stroke frequency.

\section{METHODS}

We invited wheelchair users from our rehabilitation unit patient database to participate in the study. We included people with chronic (12 months) C6 SCI American Spinal Injury Association (ASIA) level A according to ASIA Classification [20]. All of them had completed a standard rehabilitation program, including wheelchair training, and had normal upper-limb, trunk, and pelvis ROM. All subjects had been using different models of rigid-frame manual wheelchairs. Axle position varied among the study population. We excluded people with chronic upper-limb pain, associated traumatic brain injury, dementia, drug or alcohol abuse, psychiatric condition, heart failure, respiratory diseases, or any other clinical condition that precluded their participation in the trial.

We studied eight subjects with C6 SCI ASIA level A. All of them reported using manual wheelchair propulsion at their homes. Table 1 details subject characteristics.

We evaluated subjects in a Motion Analysis Laboratory (BTS ELITE [BTS Bioengineering; Milan, Italy]). We positioned six infrared cameras $(100 \mathrm{~Hz})$ surrounding a capture volume of $600 \mathrm{~cm} \times 150 \mathrm{~cm} \times 180 \mathrm{~cm}$. The system collected the coordinates of retroreflective markers attached to the right acromial end, C7 vertebrae, sacrum, right olecranon, styloid process of the radius and ulna, third metacarpal head, and wheel axis. We placed two additional markers on the wheels at a fixed distance from the axis. We placed the markers unilaterally on the right side of the subject and wheelchair. We placed the sacral marker on the wheelchair backrest to avoid optical occlusion. To locate the right position of the sacrum, we generated one virtual marker in processing time, referred to the original sacral marker at a distance equivalent to the chair-back width. We calculated upper-limb angular kinematics using the method described by Rab et al. [21]. We performed data acquisition and processing using the BTS SMART-Analyzer (BTS Bioengineering).

Table 1.

Subject characteristics.

\begin{tabular}{ccccccc}
\hline Participant & Age (yr) & Sex & $\begin{array}{c}\text { ASIA } \\
\text { (motor level) }\end{array}$ & Weight (kg) & Height (cm) & $\begin{array}{c}\text { Time Since } \\
\text { Injury (mo) }\end{array}$ \\
\hline 1 & & & M & C6 A & 90 & 180 \\
2 & 23 & M & C6 A & 68 & 176 \\
3 & 17 & M & C6 A & 82 & 182 & 180 \\
4 & 27 & M & C6 A & 80 & 74 \\
5 & 23 & M & C6 A & 70 & 175 \\
6 & 33 & M & C6 A & 84 & 173 \\
7 & 44 & M & C6 A & 73 & 173 \\
8 & 57 & M & C6 A & 65 & 37 \\
\hline
\end{tabular}

ASIA = American Spinal Injury Association, C6 A = C6 tetraplegia at ASIA level A, M = male. 


\section{Adjustable Wheelchair}

We used a Quickie R2 rigid-frame ultra-lightweight wheelchair (Sunrise Medical; Longmont, Colorado) with 26 in. $(66 \mathrm{~cm})$ diameter rear wheels, 23 in. $(59 \mathrm{~cm})$ plasticcoated hand rim, 4 in. $(10 \mathrm{~cm})$ polyurethane front wheels, 16 in. $(41 \mathrm{~cm})$ seat width, 16 in. $(41 \mathrm{~cm})$ seat depth, $0^{\circ}$ camber angle, and medium backrest with a JAY 2 cushion (Southwest Medical; Phoenix, Arizona). We modified the rear axle position on the longitudinal direction $(x)$ and the vertical direction $(y)$. We defined four rear axle positions according to the most commonly prescribed settings in our rehabilitation clinic: up and forward (position 1), down and forward (position 2), down and backward (position 3), and up and backward (position 4). Moving the axle forward generates a seat unit that is posterior relative to the rear wheels, and moving the axle backward results in a seat unit that is anterior relative to the rear wheels. Moving down the posterior seat resulted in a seat unit that is lower relative to the rear wheels, and moving up the posterior seat resulted in a seat unit that is higher relative to the rear wheels. In the four axle positions, the backrest angle was the same. We standardized subjects' positions to the wheelchair using a marker on the shoulder to axle position 4 at a $0.752 \pm 0.024 \mathrm{~m}$ distance (mean \pm standard deviation). We then modified axle position on the anterior by 0.25 in. $(0.63 \mathrm{~cm})$ and 1.75 in. $(4.44 \mathrm{~cm})$ in relation to the backrest and downward 4.5 in. $(11.4 \mathrm{~cm})$ and 6.5 in. $(16.5 \mathrm{~cm})$ in relation to the seat (Figure). We adjusted the backrest and footrest heights of the wheelchair so that they were similar to the subjects' personal wheelchairs.

\section{Data Collection}

We collected data as participants propelled the instrumented wheelchair over a $10 \mathrm{~m}$ section of smooth, level vinyl floor. Prior to data collection, each subject had a 5 min warm-up session. We instructed subjects to propel the wheelchair for five trials at maximum speed. The first two trials served as practice sessions so subjects could become familiar with the test conditions. Subjects then continued with the other three trials, which we used for data recording. In between trials, subjects had $5 \mathrm{~min}$ breaks. Each trial consisted of one ramp upstroke from standstill and two full start-up strokes (that were analyzed). We defined a propulsion cycle as the initial contact between the subjects' hands and the wheelchair hand rim until the next contact. We obtained the initial contact

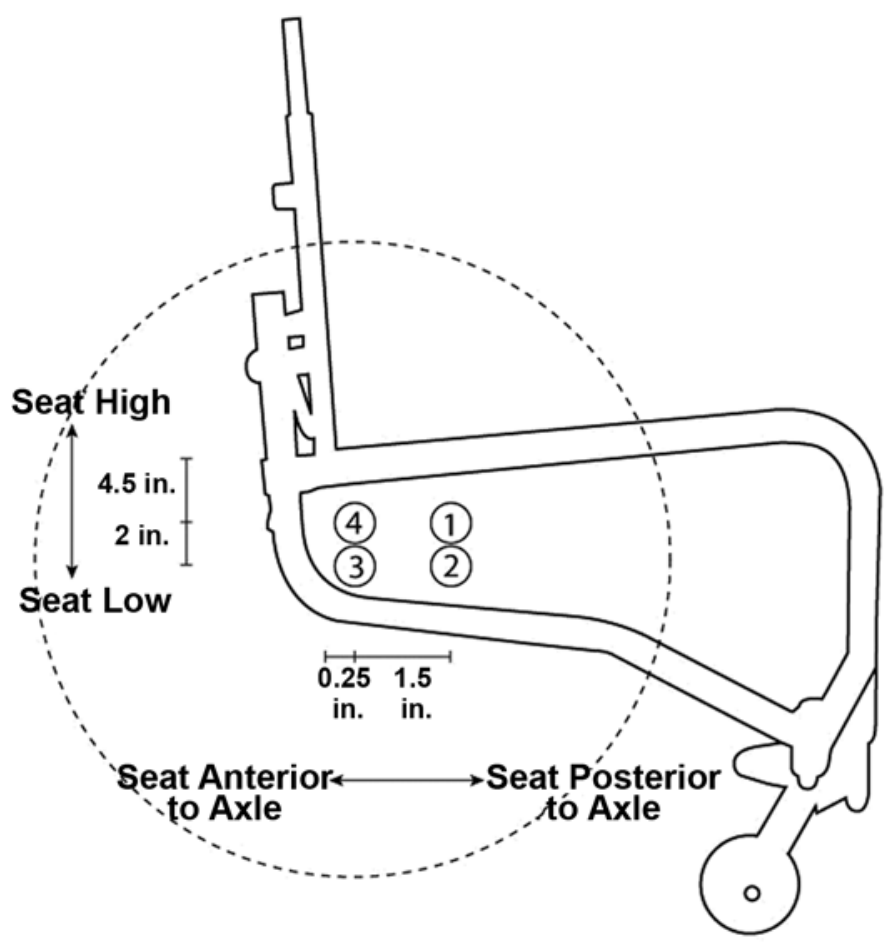

Figure.

Seat position matrix. $1=$ position $1,2=$ position $2,3=$ position 3 , and $4=$ position 4.

by visual cues using the vertical coordinates from the center of rotation of the wrist.

We randomly modified axle positions for each subject. The subjects were fastened to the wheelchair by a safety strap at the middle of their trunk to avoid a fall at sudden deceleration.

\section{Data Analysis}

We analyzed speed, acceleration, stroke frequency, and shoulder ROM. We calculated speed and acceleration as the average of the instant values during the entire trial. We calculated speed as the average value of the linear velocity of the sacral marker. We obtained the acceleration as a first temporal derivative of velocity. We defined stroke frequency as the number of propulsion cycles per minute. We obtained the shoulder ROM as the difference between the maximum and minimum degrees of the shoulder rotation curves in the three different planes. The final value is the average of the two strokes and the three trials analyzed for each subject.

We analyzed data for significant statistical differences using the Wilcoxon signed rank test and the Friedman test. We set statistical significance at $p<0.05$. 


\section{RESULTS}

\section{Speed}

Table 2 shows the speed at different axle positions. We observed significant differences in the speed for the different axle positions. Position 1 (up and forward axle) obtained the highest speed, showing significant differences compared with all other positions. Position 3 (down and backward axle) showed the lowest speed (Table 3).

\section{Acceleration}

Table 2 shows the acceleration at different axle positions. We observed significant differences in the acceleration for the different axle positions. We did not see significant differences between positions 1,2 , and 4 . We saw the least acceleration capacity in position 3 (down and backward axle), with significant differences compared with the other axle positions (Table 3).

\section{Stroke Frequency}

Table 2 shows the stroke frequency at different axle positions. We observed significant differences in the stroke frequency for the different axle positions. The stroke frequency in position 1 was significantly higher than in positions 2 and 3 . The stroke frequency in position 4 was also higher compared with positions 2 and 3 (Table 3).

\section{Shoulder Range of Motion}

The data collection recorded from the Motion Analysis Laboratory showed a decreased shoulder ROM in position 1 compared with positions 2 and 3 at the transversal plane. The shoulder ROM in position 4 was less than position 3 in the transversal plane. We found no significant shoulder ROM differences in the coronal and sagittal planes (Tables 4 and 5).

\section{Axle Positions}

Considering the variables mentioned earlier, our study showed that-

1. At position 1 (up and forward axle), subjects reached the highest speed, showing significant differences compared with all other positions. Position 1also had a higher stroke frequency and a shorter shoulder ROM in the transversal plane in positions 2 and 3.

Table 2 .

Speed, acceleration, and stroke frequency at different axle positions.

\begin{tabular}{|c|c|c|c|c|c|}
\hline \multirow{2}{*}{ Kinematic Parameter } & \multicolumn{4}{|c|}{ Axle Position } & \multirow{2}{*}{ Friedman Test } \\
\hline & 1 (UF) & 2 (DF) & 3 (DB) & 4 (UB) & \\
\hline \multicolumn{6}{|l|}{ Speed (m/s) } \\
\hline Median & 1.10 & 1.02 & 1.01 & 1.07 & $\chi^{2}=18.60$ \\
\hline Min-Max & $0.97-1.34$ & $0.91-1.30$ & $0.83-1.13$ & $0.95-1.22$ & $p<0.001^{*}$ \\
\hline \multicolumn{6}{|l|}{ Acceleration (m/s $\left.{ }^{2}\right)$} \\
\hline Median & 0.085 & 0.077 & 0.049 & 0.084 & $\chi^{2}=11.85$ \\
\hline Min-Max & $0.07-0.38$ & $0.05-0.25$ & $0.03-0.09$ & $0.07-0.12$ & $p=0.01^{*}$ \\
\hline \multicolumn{6}{|l|}{ Stroke Frequency (cycles/s) } \\
\hline Median & 0.95 & 0.92 & 0.92 & 0.93 & $\chi^{2}=8.46$ \\
\hline Min-Max & $0.86-1.04$ & $0.80-1.02$ & $0.85-0.93$ & $0.86-0.97$ & $p=0.37^{*}$ \\
\hline
\end{tabular}

${ }^{*}$ Significance level set at $p<0.05$.

$\mathrm{DB}=$ down and backward axle, $\mathrm{DF}=$ down and forward axle, Max = maximum, Min = minimum, UB = up and backward axle, UF = up and forward axle.

Table 3.

Speed, acceleration, and stroke frequency at different axle positions by Wilcoxon signed rank test.

\begin{tabular}{|c|c|c|c|c|c|c|}
\hline \multirow{2}{*}{ Kinematic Parameter } & \multicolumn{6}{|c|}{ Comparison of Related Pairs (Axle Position) } \\
\hline & 1 vs 2 & 1 vs 3 & 1 vs 4 & 2 vs 3 & 2 vs 4 & 3 vs 4 \\
\hline Speed ( $p$-value) & $0.01^{*}$ & $0.01^{*}$ & $0.01^{*}$ & $0.04^{*}$ & 0.89 & $0.12^{*}$ \\
\hline Stroke Frequency ( $p$-value) & $0.01^{*}$ & $0.05^{*}$ & 0.21 & 0.33 & 0.89 & $0.01^{*}$ \\
\hline
\end{tabular}


Table 4.

Shoulder range of motion at different axle positions.

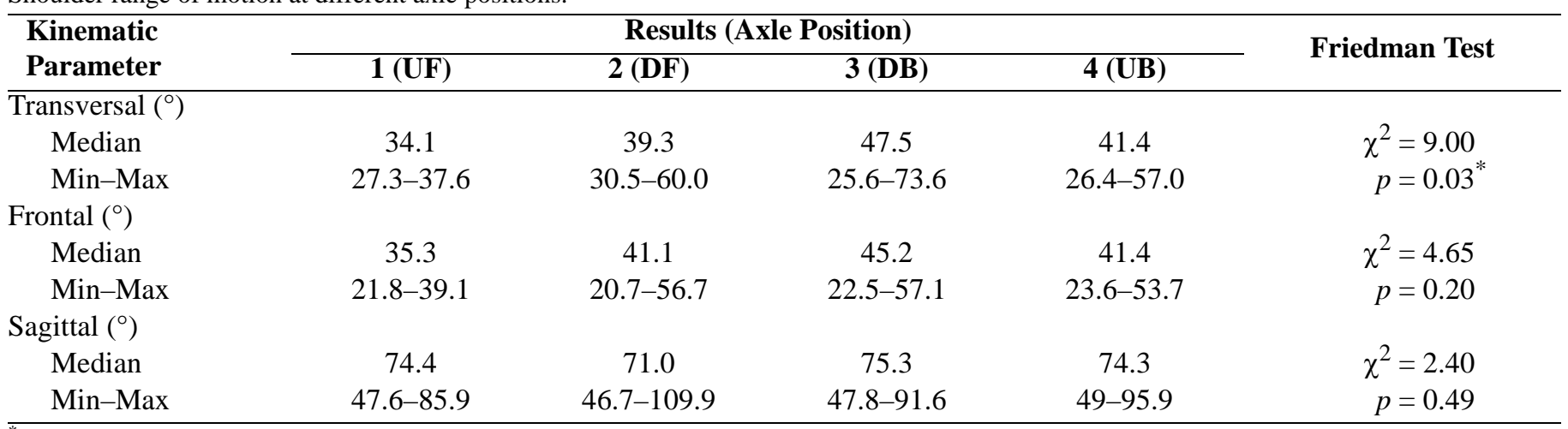

*Significance level set at $p<0.05$.

$\mathrm{DB}=$ down and backward axle, $\mathrm{DF}=$ down and forward axle, Max = maximum, Min = minimum, UB = up and backward axle, UF = up and forward axle.

Table 5.

Shoulder range of motion at different axle positions by Wilcoxon signed rank test.

\begin{tabular}{|c|c|c|c|c|c|c|}
\hline \multirow{2}{*}{$\begin{array}{l}\text { Kinematic } \\
\text { Parameters }\end{array}$} & \multicolumn{6}{|c|}{ Comparison of Related Pairs (Axle Position) } \\
\hline & 1 vs 2 & 1 vs 3 & 1 vs 4 & 2 vs 3 & 2 vs 4 & 3 vs 4 \\
\hline Transversal ( $p$-value) & $0.01^{*}$ & $0.04^{*}$ & 0.07 & 0.12 & 0.16 & $0.03^{*}$ \\
\hline Sagittal ( $p$-value) & 0.48 & 0.16 & $0.05^{*}$ & 0.58 & 0.58 & 0.48 \\
\hline
\end{tabular}

2. At position 2 (down and forward axle), subjects reached a lower speed than in position 1 but higher than in position 3 . The stoke frequency was lower and the shoulder ROM in the transversal plane was increased compared with position 1 .

3. At position 3 (down and backward axle), subjects reached the lowest speed, used the lowest acceleration, and used a lower stroke frequency than in positions 1 and 4. Also, we observed the greatest shoulder ROM in the transversal plane in this position.

4. At position 4 (up and backward axle), subjects reached a lower speed than in position 1 but higher speed than in position 3. The stroke frequency was increased compared with position 3. Also, we observed a decreased shoulder ROM in the transversal plane compared with position 3.

\section{DISCUSSION}

Achieving ambulatory independence continues to be a real challenge for patients with motor C6 SCI. While most patients with paraplegia will easily gain training with wheelchairs, those with motor C6 SCI are a special subset of patients given their multiple deficits in muscle strength. Harburn and Spaulding reported a higher intensity of muscular activity in the subjects with tetraplegia compared with subjects without disability and subjects with paraplegia [22]. Mulroy et al. determined that a further decreased velocity in people with C6 tetraplegia can be partially attributed to a lack of functional triceps activity and reduced biceps activation [19]. In our study, although we consider the muscular activity to be an important variable, we did not measure it. We determined whether changes in axle position, which are usually made in the clinical setting, would result in a significant change in speed, acceleration, stroke frequency, and shoulder ROM in people with C6 tetraplegia.

Our results demonstrate that subjects in position 1 (up and forward axle) reached the highest speed, had a higher stroke frequency, reached a higher acceleration, and achieved a shorter shoulder ROM in the transversal plane. In contrast to these results, Kotajarvi et al. found that seat position changes had no effect on wheelchair speed and stroke frequency in people with paraplegia [13]. Other researchers of wheelchair propulsion placed 
subjects on a wheelchair ergometer with split rollers at a constant speed, finding that the low and posterior seat positions decreased the stroke frequency [6]. It is important to mention that Boninger et al.'s study showed that decreasing the frequency of propulsion and reducing the rate of rise of force may help prevent median nerve injury and thus carpal tunnel syndrome [12].

On the other hand, in position 3 (down and backward axle), subjects reached the lowest speed, reached the lowest acceleration, and had the lowest stroke frequency. Also, we observed the highest shoulder ROM in the transversal plane in this position. These results are related to Brubaker's study, which noted that propulsion efficiency is significantly affected by the user's position relative to the axle and advocated a posterior seat position to decrease rolling resistance and increase propulsion efficiency [11]. Also, Boninger et al. determined that a shorter vertical distance between the axle and shoulder and a more forward axle position were correlated with improvements in wheelchair propulsion biomechanics [12].

In our study, all of the subjects in the different axle positions were within the parameters described by Van der Woude et al. They reported that the ideal seat height is the point at which the angle between the upper arm and forearm is between $100^{\circ}$ and $120^{\circ}$ when the hand is resting on the top dead center of the pushrim [23].

Although the ideal condition would be high speed and acceleration with a low stroke frequency, according to the literature and our own knowledge, we suggest that the up and forward axle position is the most suitable for patients with tetraplegia because this position improves acceleration and speed with a shorter shoulder ROM. These variables are essential for the propulsion of the wheelchair in the patient's home, given the short distances required there. We must note that these patients are mainly using their wheelchairs in their homes. It is also important to consider other factors when determining the proper setup, such as anthropometry and activity level, among others. Furthermore, axle positions have other everyday implications such as a decrease in turning radius, a decrease in the downhill turning tendency when on a slanted surface, a decrease of flutter in the front casters, etc.

In our study, we found that the stroke frequency is increased in the up and forward axle position. Further studies will determine whether this is due to the fact that we analyzed start-up strokes and that we performed the study over a smooth surface.

The present study is limited, though, by the fact that the subjects were all male, the seat width was not adjust- able (all subjects could fit and none reported complaints), the backrest was the same for all participants (none reported complaints), and the analysis was only based on two start-up strokes. Subsequent studies should take into consideration aspects such as electromyographic muscle activity, kinetic data using a force and torque sensing pushrim, and oxygen uptake to determine the most efficient axle position for people with chronic C6 tetraplegia. Future studies will determine if any differences exist for with people with C7 tetraplegia, since the triceps plays an essential role in the propulsion in this particular population. In addition to this, our results will also need to be compared with future studies about steady-state propulsion in this population.

\section{CONCLUSIONS}

The up and forward axle position resulted in an increase in speed and acceleration with a higher stroke frequency and decreased shoulder ROM. The down and backward axle position resulted in the lowest speed and acceleration with a lower stroke frequency and increased shoulder ROM. These findings are extremely important for these subjects.

\section{ACKNOWLEDGMENTS}

\section{Author Contributions:}

Study concept and design: O. Freixes.

Acquisition of data: M. J. Crespo.

Analysis and interpretation of data: O. Freixes, S. A. Fernández. Drafting of manuscript: I. F. Rubel, L. E. Olmos.

Critical revision of manuscript for important intellectual content: I. F. Rubel, L. E. Olmos.

Statistical analysis: O. Freixes, S. A. Fernández, M. A. Gatti. Administrative, technical, and material support: O. Freixes,

S. A. Fernández.

Study supervision: O. Freixes.

Financial Disclosures: The authors have declared that no competing interests exist.

Funding/Support: This material was unfunded at the time of manuscript preparation.

Additional Contributions: We would like to thank Gustavo Wright and physical therapists Oscar Alzúa and Vanesa Bochkezanian for their valuable contributions to this article.

Institutional Review: This study was approved by the institutional review board and ethics committee of the Fleni Institute. All subjects provided informed consent. We followed procedures in accordance with institutional guidelines. 
Participant Follow-Up: The authors plan to inform participants of the publication of this study.

\section{REFERENCES}

1. Davis JL, Growney ES, Johnson ME, Iuliano BA, An KN. Three-dimensional kinematics of the shoulder complex during wheelchair propulsion: A technical report. J Rehabil Res Dev. 1998;35(1):61-72. [PMID: 9505254]

2. Rudins A, Laskowski ER, Growney ES, Cahalan TD, An KN. Kinematics of the elbow during wheelchair propulsion: A comparison of two wheelchairs and two stroking techniques. Arch Phys Med Rehabil. 1997;78(11):1204-10.

[PMID: 9365350]

DOI:10.1016/S0003-9993(97)90333-6

3. Boninger ML, Cooper RA, Baldwin MA, Shimada SD, Koontz A. Wheelchair pushrim kinetics: Body weight and median nerve function. Arch Phys Med Rehabil. 1999; 80(8):910-15. [PMID: 10453767] DOI:10.1016/S0003-9993(99)90082-5

4. Robertson RN, Boninger ML, Cooper RA, Shimada SD. Pushrim forces and joint kinetics during wheelchair propulsion. Arch Phys Med Rehabil. 1996;77(9):856-64.

[PMID: 8822674]

DOI:10.1016/S0003-9993(96)90270-1

5. Paralyzed Veterans of American Consortium for Spinal Cord Medicine. Preservation of upper limb function following spinal cord injury: A clinical practice guideline for health-care professionals. J Spinal Cord Med. 2005;28(5): 434-70. [PMID: 16869091]

6. Mâsse LC, Lamontagne M, O’Riain MD. Biomechanical analysis of wheelchair propulsion for various seating positions. J Rehabil Res Dev. 1992;29(3):12-28.

[PMID: 1640378$]$

DOI:10.1682/JRRD.1992.07.0012

7. Mulroy SJ, Gronley JK, Newsam CJ, Perry J. Electromyographic activity of shoulder muscles during wheelchair propulsion by paraplegic persons. Arch Phys Med Rehabil. 1996;77(2):187-93. [PMID: 8607745]

DOI:10.1016/S0003-9993(96)90166-5

8. Veeger HE, Meershoek LS, Van der Woude LH, Langenhoff JM. Wrist motion in handrim wheelchair propulsion. J Rehabil Res Dev. 1998;35(3):305-13. [PMID: 9704314]

9. Rodgers MM, Keyser RE, Gardner ER, Russell PJ, Gorman PH. Influence of trunk flexion on biomechanics of wheelchair propulsion. J Rehabil Res Dev. 2000;37(3): 283-95. [PMID: 10917260]

10. Richter WM. The effect of seat position on manual wheelchair propulsion biomechanics: A quasi-static model-based approach. Med Eng Phys. 2001;23(10):707-12.

[PMID: 11801412]

DOI:10.1016/S1350-4533(01)00074-1
11. Brubaker CE. Wheelchair prescription: An analysis of factors that affect mobility and performance. J Rehabil Res Dev. 1986;23(4):19-26. [PMID: 3820118]

12. Boninger ML, Baldwin M, Cooper RA, Koontz A, Chan L. Manual wheelchair pushrim biomechanics and axle position. Arch Phys Med Rehabil. 2000;81(5):608-13.

[PMID: 10807100] DOI:10.1016/S0003-9993(00)90043-1

13. Kotajarvi BR, Sabick MB, An KN, Zhao KD, Kaufman KR, Basford JR. The effect of seat position on wheelchair propulsion biomechanics. J Rehabil Res Dev. 2004;41(3B): 403-14. [PMID: 15543458] DOI:10.1682/JRRD.2003.01.0008

14. Cowan RE, Nash MS, Collinger JL, Koontz AM, Boninger ML. Impact of surface type, wheelchair weight, and axle position on wheelchair propulsion by novice older adults. Arch Phys Med Rehabil. 2009;90(7):1076-83.

[PMID: 19577019$]$

DOI:10.1016/j.apmr.2008.10.034

15. Dalyan M, Cardenas DD, Gerard B. Upper extremity pain after spinal cord injury. Spinal Cord. 1999;37(3):191-95. [PMID: 10213328]

DOI:10.1038/sj.sc.3100802

16. Turner JA, Cardenas DD, Warms CA, McClellan CB. Chronic pain associated with spinal cord injuries: A community survey. Arch Phys Med Rehabil. 2001;82(4):501-8. [PMID: 11295011] DOI:10.1053/apmr.2001.21855

17. Kulig K, Newsam CJ, Mulroy SJ, Rao S, Gronley JK, Bontrager EL, Perry J. The effect of level of spinal cord injury on shoulder joint kinetics during manual wheelchair propulsion. Clin Biomech. 2001;16(9):744-51.

[PMID: 11714551] DOI:10.1016/S0268-0033(01)00066-3

18. Newsam CJ, Rao SS, Mulroy SJ, Gronley JK, Bontrager EL, Perry J. Three dimensional upper extremity motion during manual wheelchair propulsion in men with different levels of spinal cord injury. Gait Posture. 1999;10(3):223-32. [PMID: 10567754] DOI:10.1016/S0966-6362(99)00034-X

19. Mulroy SJ, Farookhi S, Newsam CJ, Perry J. Effects of spinal cord injury level on the activity of shoulder muscles during wheelchair propulsion: An electromyographic study. Arch Phys Med Rehabil. 2004;85(6):925-34.

[PMID: 15179646]

DOI:10.1016/j.apmr.2003.08.090

20. Maynard FM Jr, Bracken MB, Creasey G, Ditunno JF Jr, Donovan WH, Ducker TB, Garber SL, Marino RJ, Stover SL, Tator CH, Waters RL, Wilberg JE, Young W. International standards for neurological and functional classification of spinal cord injury. American Spinal Injury Association. Spinal Cord. 1997;35(5):266-74. 
JRRD, Volume 47, Number 7, 2010

[PMID: 9160449$]$

DOI:10.1038/sj.sc.3100432

21. Rab G, Petuskey K, Bagley A. A method for determination of upper extremity kinematics. Gait Posture. 2002;15(2):

113-19. [PMID: 11869904$]$ DOI:10.1016/S0966-6362(01)00155-2

22. Harburn KL, Spaulding SJ. Muscle activity in the spinal cord-injured during wheelchair ambulation. Am J Occup Ther. 1986;40(9):629-36. [PMID: 3766686]

23. Van der Woude LH, Veeger DJ, Rozendal RH, Sargeant TJ. Seat height in handrim wheelchair propulsion. J Rehabil Res Dev. 1989;26(4):31-50. [PMID: 2600867]
Submitted for publication September 17, 2009. Accepted in revised form April 27, 2010.

This article and any supplementary material should be cited as follows:

Freixes O, Fernández SA, Gatti MA, Crespo MJ, Olmos LE, Rubel IF. Wheelchair axle position effect on start-up propulsion performance of persons with tetraplegia. J Rehabil Res Dev. 2010;47(7):661-68.

DOI:10.1682/JRRD.2009.09.0146 